\title{
Weight Based Stereotyping Amongst Pre-Service Health and Physical Educators
}

\author{
Thea Werkhoven, Wayne Cotton, Kate Russell \\ The Faculty of Education and Social Work, \\ The University of Sydney, Australia
}

\begin{abstract}
The purpose of this study was to examine the fat stereotyping attitudes of pre-service health and physical educators towards overweight and obese children and to determine if these attitudes were influenced by gender or degree progression. Preservice health and physical educators $(n=38)$ completed the Fat Stereotypes Questionnaire and endorsed fat stereotyping attitudes on characteristics and attributes including laziness, attractiveness and friendship. Males and females exhibited differing attitudes during their second and third year of study with males associating happiness with thinness whereas females associated it with fatness. Attitudes towards obesity worsened longitudinally with degree progression. Thus, when fat stereotyping attitudes are held by pre-service health and physical educators they are influenced by progression of degree and gender. Further research is required to determine the effect that these attitudes have on the quality of teaching and learning provided to their students once they graduate.
\end{abstract}

\section{Introduction}

For more than two decades overweight and obesity in Australia have been at the forefront of public health campaigns and public awareness due to their prevalence in both the paediatric and adult populations. Primary and secondary education institutions across Australia have long been sites for targeted health promotion aimed at reducing paediatric and teen rates of overweight and obesity with varying levels of success [1]. Other industrialised countries such as the United Kingdom and the United States of America have also chosen educational institutions as locations to employ health promotion aimed at reducing paediatric rates of overweight and obesity by targeting both knowledge and eating behaviours [2].

With rates of overweight and obesity widely reported at epidemic status by medical professionals, statisticians and the media, both conditions continue to dominate public health campaigns aimed at prevention and methodologies for treatment [3].

\section{Literature Review}

Shifts and trends of overweight and obesity in Australia are routinely represented through quadrennial National Health Surveys that are conducted by the Australian Bureau of Statistics on behalf of the Australian Government. Most relevant to this study are paediatric rates of overweight and obesity, occurring between the ages of 5 and 17 whereby children have increased levels of adiposity compared to peers of normal weight $[4,5]$. The categorization of overweight and obesity in this age group within the National Health surveys is dependent upon self-reported measurements of height and weight which are used to calculate the Body Mass Index and compared to recommended cutoffs appropriate for each gender and age group [6].

The most recent National Health Survey in 2011/12 revealed that there had not been a change in the proportion of children (5-17 years) who were overweight or obese from the prior two survey [5]. In 2007/08, 25\% of children in this age bracket were overweight or obese, comprised of $17 \%$ overweight and $8 \%$ obese [7]. Data from 2011/12 shows that $25.3 \%$ of children were now overweight or obese, comprised of $17.7 \%$ overweight and $7.6 \%$ obese [5]. These figures show that over the past 5 years there has been stabilization in rates of paediatric overweight and obesity and that rates have plateaued. This is contrary to public perception of rates undergoing constant growth and reported epidemic status [8].

The magnitude of prevalence of paediatric overweight and obesity in Australia outweighs any disagreement that may exist regarding accepted rates. Instead, it highlights instead the importance of obesity prevention strategies that aim to lower the number of Australian children with excess adiposity.

Health risks associated with being overweight and obese regardless of age or gender are widely reported and include risk of cardiovascular disease, high blood pressure and type 2 diabetes [5] with increased propensity of developing chronic disease that impacts on all aspects of health and wellbeing. 
Being overweight or obese as a child has potential consequences for health into adulthood with children being more likely to have higher adiposity and continue unhealthy behaviours beyond their adolescence if they form these habits in early life [9, 10]. They are also more likely to become adults with decreased opportunities in employment, education, access to healthcare and be treated more negatively than their peers of normal weight [11].

Not only are the effects of paediatric overweight and obesity related to mental health and quality of life, the biomedical health is affected as well. Adolescents who are obese are more likely than their peers of normal weight to have higher blood pressure, poorer ratios of blood lipids and have higher fasting insulin levels [12]. They are also more likely to experience symptoms during period of physical activity including heat intolerance, excessive sweating, heat rash, tiredness, shortness of breath, joint pain and headaches [13].

Education related to health, nutrition and physical activity is delivered to children from a wide range of people and in many different environments, one of the most important being in school. In Australian educational institutions this formal education is delivered through the subject of Health and Physical Education (HPE), a mandatory subject for all students until midway through secondary school [14, 15]. Syllabus requirements for this subject in New South Wales include teaching health and nutrition in a way that prepares students with skills and knowledge that allow them to make healthy choices in lifestyle and physical activity throughout life [14, 15]. Due to these explicit syllabus requirements, HPE teachers appear to be more responsible for the nutrition and physical activity education for overweight and obese children than general teachers. Commonplace amongst practicing teachers is the reflection that they are often underequipped to teach in accordance with syllabus requirements as they lack appropriate levels of health and nutrition knowledge or do not have access to resources required to teach properly [16].

Alongside deficiencies in adequate knowledge to teach nutrition is a rising issue of weight based prejudice held by practicing teachers towards overweight or obese children in their classes. This prejudice has been found to exist in both practicing and pre-service teachers and results in ineffective health promotion and health education [17-19].

Weight based prejudice is an umbrella term that encompasses obesity bias, discrimination, antifat attitudes and stigmatization and occurs when an overweight or obese individual is pre-judged in a negative way [20] and is victimized [21], resulting in feeling socially unacceptable or insignificant [22]. Implications of weight based prejudice towards overweight or obese children from their educators are large [23]. Their self-esteem and body image becomes eroded [24] and their social, psychological and physical health decline as they age [25].

Of specific interest to this study are the antifat attitudes of pre-service HPE teachers and the changes in attitudes that occur over the progression of their degree from the second to their fourth and final year. Three studies completed in New Zealand, the United States of America and Britain over the past ten years show that as a cohort, pre-service educators possess prejudice, bias and antifat attitudes towards overweight and obese people and that this has the potential to effect their education style and quality.

The New Zealand study investigated prejudice in a similar group of university students enrolled in a Bachelor of Physical Education degree. Similar to the present study, participants were surveyed to investigate their prejudicial attitudes in their first and third year of their degree and attitudes were compared over time. The pre-service educators in this study displayed prejudice towards overweight and obese people which was greater in their third year of study than first and it was suggested that these attitudes were linked to belief systems and investment in physical appearance [18]. These results were similar to the earlier American study amongst tertiary students majoring in exercise science. These students exhibited bias towards obese individuals and associated them negatively with qualities such as laziness [26]. British students studying sport exercise and physical education degrees possessed similar attitudes, specifically towards obese children finding them to have lower body image, sport competence, physical condition, physical self-worth and global self-esteem than their peers of normal weight [27].

As a group, pre-service educators have been shown to be at risk of being biased towards overweight or obese students, a phenomenon especially seen in pre-service health and physical education students [19, 28]. Fat stereotyping attitudes demonstrated by pre-service educators include viewing overweight or obese children as weak willed, lazy and lacking self-control [29]. The impact of these attitudes is important as these beliefs can affect how the educators treat their students and in turn how successful the student is academically [30].

It has been suggested that attitudes of weight bias towards overweight and obese children held by preservice HPE teachers culminate due to a lack of appropriate training during their formative years in tertiary education [30]. Common attitudes explicitly expressed by pre-service educators towards overweight or obese children include the perception that they are "ugly, awkward, gluttonous, stupid and worthless"[29]. A possible reason identified for educators to possess antifat attitudes is that the physical appearance of an overweight or obese child is the most apparent characteristic that assumptions 
can be made from, resulting in presumptions to be made regarding their physical capabilities, abilities and personalities [31]. As a result of the presence of stigmatizing and antifat attitudes from their educators, the school environment therefore has the potential to be detrimental to overall psychological, social and physical health of overweight or obese children in schools [32].

Key aims of this research are to a) identify if preservice health and physical educators possess fat stereotyping attitudes, b) determine if these fat stereotyping attitudes are significantly different between gender and c) determine if these fat stereotyping attitudes change from second to fourth year of study.

\section{Research methods and procedures}

The methodology employed for this study was quantitative in design and was conducted in the tertiary education setting in Australia.

\subsection{Participants}

Students enrolled in a health and physical education degree at a major University in NSW participated in this study as part of their course requirements. Participants were surveyed in three consecutive years of study, from second to fourth and final year. At the time of first data collection 52 students were surveyed of which $37 \%$ were male $(\mathrm{N}=19)$ and $63 \%$ were female $(\mathrm{N}=33)$.

Retention rate to the final year of study was $67 \%$ with a higher number of female students withdrawing from the subject or choosing not to participate in the study than males. Data was collected anonymously and matched after the fact via reported dates of birth and self-reported measurements of height (to nearest $0.5 \mathrm{~cm}$ ). Mean age of females at the time of first data collection was $23(\mathrm{SD}=1)$ and mean age of males was $25(\mathrm{SD}=4)$.

\subsection{Survey}

Participants completed the Fat Stereotypes Questionnaire (FSQ) three times in consecutive years of study. The FSQ was chosen as it is a previously validated test (internal consistency ranged from $\alpha=0.65$ to 0.71 ) used on both adults and children to assess fat stereotyping attitudes and association of characteristics with either fat or thin people [11,33]. Five characteristics were assessed including happiness, intelligence, attractiveness, laziness and friendship as well as agreement with the statements that it is good/bad to be fat/thin.

The characteristic of friendship included three attributes: having lots of friends, having few friends and difficulty making friends. All other attributes measured one single characteristic. In total, nine pairs of statements were presented to study participants on a four point Likert scale from really disagree to really agree. Each pair required participants to rate their agreement with the statement for both fat and thin people. For example, "fat people are smart" and "thin people are smart".

Using the original FSQ method used by Davison and Birch, when coding the data and entering it for analysis, all statements that were negatively worded were reversed, for example "it is hard for fat people to make friends". In doing this, all scores were interpreted in the same direction. Also, this was done because participants may have been unwilling to mark their agreement with a negatively worded statement towards fat people openly and attempted to answer the questionnaire in a way that masks their attitudes or in a way that they think the researcher will find favourable [11].

Next, discrepancy scores were calculated for each attribute or statement tested. This was done by subtracting the score from a thin person attribute from a fat person attribute. For example "fat people are happy people" score - "thin people are happy people" score. Discrepancy scores $>0$ indicate that the attribute is endorsed for thin people and scores $<0$ indicate endorsement of the attribute for fat people. A score of zero indicates no prejudicial attitudes. A mean of these nine scores was taken and a higher mean score indicated greater endorsement of negative characteristics with fat people and thus higher fat stereotyping.

\subsection{Statistical Analyses}

Data was entered into SPSS V.21 for analysis [34] and a series of parametric tests were run to assess the influence of gender and degree progression on attitudes. Significance was set at $\mathrm{p}<.05$. When required, effect size for results was set in accordance with Cohen's cutoffs for eta-squared values with values of .01 being small, .06 being moderate and .14 representing a large effect [35].

\section{Results}

Parametric tests including t-tests were conducted to determine if either gender or year of study significantly influenced the fat stereotyping attitudes of participants and scores were compared between groups and across time. Although Shapiro-Wilk tests revealed that the distribution of the data was not normal the parametric tests were still utilised as the violations were small and no other assumptions were violated [36].

\subsection{Presence of stereotyping attitudes}

As a cohort, the pre-service HPE teachers 
demonstrated fat stereotyping attitudes, as seen in Table 1. These attitudes are represented in scores greater or less than zero. These attitudes were displayed for individual characteristics, attributes and agreement for weight related statements as well as represented in the overall mean score for each group.

The characteristics of having lots of friends, having few friends and the attributes of happiness and being smart are not shown in Table 1 as they were not significantly different from the expected value of zero, representing a lack of fat stereotyping attitudes.

\subsection{Gender and attitudes at each time point}

To assess the impact of gender on attitudes in each year of study, three independent sample t-tests were conducted with gender as the independent variable and fat stereotype subscale scores as the dependent variables. Results from t-tests conducted are seen in Table 2.

In second year of study the mean fat stereotyping score and 8 characteristics/attitudes were compared between males and females. There was no significant difference in fat stereotyping scores on all but one statement between genders. On the statement that it is 'good to be fat/thin', a significant difference was seen between males $(\mathrm{M}=-0.74, \mathrm{SD}=1.15)$ and females $(\mathrm{M}=-1.36, \mathrm{SD}=0.90) ; \mathrm{t}(50)=2.19, \mathrm{p}=.03$. The magnitude of the differences in scores (mean difference $=0.63,95 \% \mathrm{CI}$; 0.05 to 1.20 ) was large (eta squared $=.11$ ). This suggests that females demonstrate stronger fat stereotyping attitudes than males in their second year of study, specifically with an anti-thin bias.

Males and females in their third year of study were found to have significantly different scores on one subscale question of happiness. Males $(\mathrm{M}=0.28$, $\mathrm{SD}=0.46)$ and females $(\mathrm{M}=-0.29, \mathrm{SD}=0.81)$ both showed stereotypical attitudes of approximately the same magnitude however males were more likely to associate happiness with being thin and females associated happiness with being fat; $\mathrm{t}(40)=2.68, \mathrm{p}=$ .01 . The magnitude of difference in scores between gender (mean difference $=.57,95 \% \mathrm{CI} ; 0.14$ to 1.00 ) was large (eta squared $=.18$ ).

No significant differences were found between gender and all scores in the fourth year of study.

\subsection{Degree progression and attitudes split by gender}

To determine if there was a change in fat stereotype scores between years of study, a series of paired sample t-tests were conducted on each gender between the students' second and third, third and fourth and second and fourth year. No significant differences in mean scores were found for males across time.

Amongst females, there was a significant difference in scores on the characteristic of 'difficulty making friends' with scores becoming worse from third year of study $(\mathrm{M}=-0.08, \mathrm{SD}=0.49)$ to fourth year $(\mathrm{M}=-0.38, \mathrm{SD}=0.65), \mathrm{t}(12)=2.31$, $\mathrm{p}<.05$ (two tailed). The mean decrease in scores on this characteristic was 0.31 with a $95 \%$ confidence interval ranging from .02 to .60 . The effect size of this was large (eta squared $=.31$ ). As scores were negative this characteristic was endorsed for fat people rather than thin, representing the stereotype that fat people have difficulty making friends.

Between the second and fourth year of study the largest significant difference was seen amongst females on the attribute of happiness. Endorsement of this attitude changed from thinness in second year $(\mathrm{M}=-0.44, \mathrm{SD}=0.89)$ to fatness in fourth $(\mathrm{M}=0.19$, $\mathrm{SD}=0.91)$ and this change in score was significant, $\mathrm{t}(15)=-2.61, \mathrm{p}<.05$. With larger scores representing higher levels of fat stereotyping attitude regardless of endorsement for fat/thin, attitudes in second year of study are seen to be worse than in fourth year. The mean change in score on this attribute was -0.63 with a $95 \%$ confidence interval ranging from -1.14 to 0.12 . Again, the effect size was large (eta squared $=$ $.31)$.

\section{Discussion}

The FSQ was developed for use in both adults and children and in the first study completed that used it, stereotyping attitudes were found across all groups with positive characteristics associated with thin people and negative characteristics with fat people [11].

The presence of fat stereotyping attitudes is mirrored in this study as the pre-service HPE educators also demonstrated small to medium levels of stereotypical attitudes on various characteristics and statements about fat and thin people. Where Davison and Birch [11] found statistically significant endorsements of negative attitudes towards each of the nine characteristics or statements tested, this study found significant endorsement for three characteristics and two statements; difficulty making friends, attractiveness, laziness and it is good to be fat/thin and it is bad to be fat/thin.

In the 2004 study [11] the attitude that it was bad to be fat and good to be thin were found in both children and adults as expected however in the present study answers provided indicated that there was the significant belief that it was both good to be fat and bad to be fat. The degree however to which these attitudes were exhibited were small with values close to zero, indicating that no strong attitudes were held by the pre-service HPE teachers for the good/bad statements. 
Table 1. Characteristics and attributes on the Fat Stereotypes Questionnaire found to be significantly different from zero for the cohort in each year of study surveyed.

\begin{tabular}{|l|c|c|c|c|c|c|c|c|c|c|c|c|}
\hline & \multicolumn{4}{|c|}{$2^{\text {nd }}$ Year } & \multicolumn{4}{c|}{$3^{\text {rd }}$ Year } & \multicolumn{4}{c|}{$4^{\text {th }}$ Year } \\
\cline { 2 - 14 } & \multicolumn{2}{|c|}{$\mathrm{n}=19$} & \multicolumn{2}{|c|}{$\mathrm{n}=33$} & \multicolumn{2}{c|}{$\mathrm{n}=18$} & \multicolumn{2}{c|}{$\mathrm{n}=24$} & \multicolumn{2}{c|}{$\mathrm{n}=15$} & \multicolumn{2}{c|}{$\mathrm{n}=20$} \\
\cline { 2 - 14 } & \multicolumn{2}{|c|}{ Males } & \multicolumn{2}{c|}{ Females } & \multicolumn{2}{c|}{ Males } & \multicolumn{2}{c|}{ Females } & \multicolumn{2}{c|}{ Males } & \multicolumn{2}{c|}{ Females } \\
\hline Stereotype & Mean & SD & Mean & SD & Mean & SD & Mean & SD & Mean & SD & Mean & SD \\
\hline Lots of friends & 0.11 & 0.94 & 0.06 & 0.90 & 0.11 & 0.68 & -0.04 & 0.69 & 0.00 & 0.38 & 0.15 & 0.81 \\
\hline Good to be & -0.74 & 1.15 & -1.36 & $0.90^{*}$ & -0.94 & 0.80 & -1.25 & 1.03 & -0.80 & 1.01 & -1.35 & 0.93 \\
\hline Bad to be & -0.58 & 0.96 & -0.79 & 1.22 & -0.28 & 0.90 & -0.67 & 0.87 & -0.33 & 1.18 & -0.85 & 1.04 \\
\hline Happy & -0.05 & 0.91 & -0.18 & 0.88 & 0.28 & 0.46 & -0.29 & $0.81 *$ & 0.13 & 0.74 & 0.10 & 0.85 \\
\hline $\begin{array}{l}\text { Difficulty making } \\
\text { friends }\end{array}$ & -0.16 & 0.77 & -0.33 & 0.60 & 0.06 & 0.42 & -0.21 & 0.72 & -0.20 & 0.56 & -0.30 & 0.57 \\
\hline Have few friends & -0.05 & 0.85 & -0.12 & 0.86 & 0.00 & 0.84 & 0.00 & 0.59 & -0.07 & 0.70 & 0.05 & 0.61 \\
\hline Smart & -0.05 & 0.23 & 0.03 & 0.53 & 0.22 & 0.43 & 0.00 & 0.66 & -0.07 & 0.46 & 0.00 & 0.46 \\
\hline Good looking & -0.47 & 0.70 & -0.39 & 1.00 & -0.61 & 0.70 & -0.38 & 0.65 & -0.47 & 1.19 & -0.35 & 1.09 \\
\hline Lazy & -0.58 & 0.69 & -0.39 & 0.86 & -0.28 & 0.83 & -0.21 & 0.66 & -0.40 & 0.83 & -0.15 & 0.49 \\
\hline Mean score & -0.29 & 0.42 & -0.39 & 0.40 & -0.17 & 0.29 & -0.34 & 0.47 & -0.24 & 0.48 & -0.30 & 0.49 \\
\hline
\end{tabular}

Table 2. Mean discrepancy scores for each attribute/characteristic tested by the Fat Stereotypes Questionnaire for both males and females in each year of study surveyed. Note, * indicates a significant t-test result, $\mathrm{p}<0.05$

\begin{tabular}{|c|c|c|c|c|c|c|c|c|c|c|c|c|c|c|c|}
\hline & \multirow{2}{*}{\multicolumn{5}{|c|}{$2^{\text {nd }}$ Year }} & \multirow{2}{*}{\multicolumn{5}{|c|}{$\frac{3^{\text {rd }} \text { Year }}{n=42}$}} & \multicolumn{5}{|c|}{$4^{\text {th }}$ Year } \\
\hline & & & & & & & & & & & & & $=35$ & & \\
\hline & Mean & SD & $\mathrm{t}$ & $\mathrm{df}$ & $\mathrm{p}$ & Mean & SD & $\mathrm{t}$ & $\mathrm{df}$ & $\mathrm{p}$ & Mean & SD & $\mathrm{t}$ & $\mathrm{df}$ & $\mathrm{p}$ \\
\hline Good to be & -1.13 & 1.03 & -7.95 & 51 & $<.001$ & -1.12 & 0.94 & -7.7 & 41 & $<.001$ & -1.11 & 0.99 & -6.64 & 34 & $\begin{array}{l}k .0 \\
01\end{array}$ \\
\hline Bad to be & -0.71 & 1.13 & -4.56 & 51 & $<.001$ & -0.50 & 0.89 & -3.64 & 41 & $<.01$ & -0.63 & 1.11 & -3.34 & 34 & $\begin{array}{l}\text { k.0 } \\
05\end{array}$ \\
\hline $\begin{array}{l}\text { Difficulty } \\
\text { making friends }\end{array}$ & -0.27 & 0.66 & -2.94 & 51 & $<.01$ & -0.10 & 0.62 & & & & -0.26 & 0.56 & -2.71 & 34 & $\begin{array}{l}.0 \\
5 \\
\end{array}$ \\
\hline Good looking & -0.42 & 0.87 & -3.5 & 51 & $<.005$ & -0.48 & 0.67 & -4.6 & 41 & $<.001$ & -0.40 & 1.12 & -2.12 & 34 & $\begin{array}{c}4.0 \\
5 \\
\end{array}$ \\
\hline Lazy & -0.46 & 0.80 & -4.14 & 51 & $<.001$ & -0.24 & 0.73 & -2.13 & 41 & $<.05$ & -0.26 & 0.66 & -2.32 & 34 & $\begin{array}{l}8.0 \\
5\end{array}$ \\
\hline Mean Score & -0.35 & 0.41 & -6.2 & 51 & $<.001$ & -0.27 & 0.41 & -4.22 & 41 & $<.001$ & -0.28 & 0.48 & -3.43 & 34 & $\begin{array}{l}k .0 \\
05\end{array}$ \\
\hline
\end{tabular}

Just as Davison and Birch's participants were significantly likely to attribute laziness and having difficulty making friends with fat people, the preservice HPE teachers in this study exhibited similar attitudes finding fat people more likely to have difficulty making friends and be lazy than thin people. One difference in significant results between this study and Davison and Birch's study is for the characteristic of attractiveness. The 2004 participants attributed being good looking with being thin whereas the pre-service HPE teachers were more likely to attribute attractiveness with being fat, although the degree of attitudes were small with scores not deviating far from zero.

The overall degree of fat stereotyping attitudes held by participants in this study were also not as high as those observed in Davison and Birch's study which recorded a total fat stereotype score of $0.43 \pm$
0.03 for females and $0.40 \pm 0.03$ for males indicating a preference for thinness over fatness. In this study, the total score across the three years ranged from $0.27 \pm 0.41$ to $-0.35 \pm 0.41$ with the negative score indicating endorsement of the characteristics for fat people and a small degree of fat stereotyping.

The presence of fat stereotyping attitudes amongst pre-service educators is not novel with previous research demonstrating negative attitudes and stereotyping towards overweight and obese children by pre-service physical educators [37]. Not only have these attitudes been found in pre-service educators but ones practicing in schools who view thin children as happy compared to fat children who were perceived as lazy and having difficulty making friends [17]. The presence of negative attitudes amongst practicing teachers points to the importance of identifying and ameliorating any weight bias prior 
to graduation and placement as health educators in schools.

Specifically within the Australian context, the obesity bias of tertiary students in their final year of a health related degree was compared to non health students, similar to this study as the cohort were in their final year of study and were destined to be employed in positions involving health promotion and obesity management. Key findings of the study were that students enrolled in health related degrees possessed significant levels of obesity bias as did those who were not, often reporting that obese individuals lacked willpower [38]. This local research points to the need for a pedagogical approach towards reducing negative attitudes towards obesity, employed in tertiary institutions with existing health curricula.

Consistently across each year of study, $90 \%$ of the total sample in the present study demonstrated stereotypical attitudes, slightly higher than the reported average $83 \%$ in Greenleaf, Martin and Rhea's study [39] conducted on male and female college students aged between 18 and 45, although the bulk of scores indicated that the degree of stereotyping was not large as scores were close to zero. While negative traits were associated with fatness in this research, an Italian study found the opposite was true for a group of female psychology students who when surveyed with the FSQ attributed mainly positive traits with fatness in other females such as happiness [40].

When comparing attitudes across all three years of study, fatness was associated with both negative and positive qualities. Positive aspects included agreement on the statement that it was good to be fat, that fat people were smart, happy and good looking. Negative qualities endorsed included laziness, having few friends and it generally being bad to be fat. Consistently in each year of study thinness was equated with the ability to have lots of friends and overall mean score represented a bias towards fat people.

Implications of these attitudes are far reaching to the health and physical education provided to overweight youth as previous research has shown that personal beliefs and attitudes held by educators can influence both the quality and quantity negatively [39]. Repercussions of this include a decrease in the motivation, performance and enjoyment of health and physical education by obese youth as well as lower expectations for physical tasks and less frequent feedback provided to them by educators with bias [41].

Significant differences in anti-thin attitudes between females and males in their second year of study were unpredicted and although were not statistically significant in the following two years of study, remained consistently biased between each gender. The agreement with the statement of it being 'good to be fat' may be due to the fact that participants may have been reluctant to openly agree with attributes for fatness that would reveal their bias explicitly. By providing participants with the option of agreeing with the attribute for thinness as well the questionnaire was designed to combat this however it is possible that participants were aware of possible identification of negative attitudes and answered accordingly [33]. Gender also influenced attitudes in third year of study on perception of happiness and fatness. Interestingly, males in their third year of study were more likely to associate happiness with thinness (pro thin) whereas females associated it with fatness (pro fat). This significant difference in bias was not seen for any other characteristics or attributes nor in other years of study.

Degree progression was seen to have the largest impact on perception of happiness and friendship of fat people by participants with largest changes in attitudes occurring between second and fourth year of study. This suggests that stereotyping based upon weight increases as education advances although more research is required to determine which factors influence this change amongst pre-service HPE teachers.

Limitations of this study include the small sample size in each year group especially after splitting by gender. Other information known to influence stereotyping attitudes include level of education, ethnicity, eating behaviours and level of preoccupation with physical appearance [33] and these factors were not measured in the current study. Given the nature of how the sample was collected as one of convenience, caution must be used in comparing the participants to other groups of preservice educators as the group may not accurately represent the typical group of pre-service HPE teachers in Australian or worldwide schools. Also, women have been found to show lower levels of obesity based stigmatization and stereotyping than men and this may have influenced the mean scores of this study as the proportion of females was higher than males [42]. Also, no comparison group was used in this study who were not undertaking a health related degree to compare attitudes against.

Future research conducted into this area of weight bias can explore other factors influencing attitudes including extrinsic and intrinsic ones and ways to measure the quality of education provided to overweight or obese children as practicing teachers. While the levels of weight bias found in this study were low their presence amongst the cohort suggest that pedagogical approaches to combatting obesity bias are required in Australian tertiary educational institutions with the aim of mitigating negative attitudes that effect the education of obese children. 


\section{References}

[1] O'Dea, J., School-based health education strategies for the improvement of body image and prevention of eating problems: An overview of safe and successful interventions. Health Education, 2005. 105(1): p. 11-33.

[2] Danielsdottir, S., K. O'Brien, and A. Ciao, Anti-Fat Prejudice Reduction: A Review of Published Studies. Obesity Facts, 2010. 3(1): p. 47-58.

[3] O'Hara, B.J., et al., Process evaluation of the advertising campaign for the NSW Get Healthy Information and Coaching Service. Health promotion journal of Australia : official journal of Australian Association of Health Promotion Professionals, 2011. 22(1): p. 68-71.

[4] Wang, Y. and T. Lobstein, Worldwide trends in childhood overweight and obesity. International Journal of Pediatric Obesity, 2006. 1(1): p. 11-25.

[5] Australian Bureau of Statistics, Australian Health Survey: First Results, 2011-12 2012, ABS, Document Number 4364.0.55.001: Canberra, ACT.

[6] National Health and Medical Research Council, Clinical Practice Guidelines for the Management of Overweight and Obesity in Adults, Adolescents and Children in Australia (2013). 2013, Australian Government, Department of Health, NHMRC: Melbourne.

[7] Australian Bureau of Statistics, National Health Survey: summary of results, 2007-08 (Reissue). 2009, ABS: Canberra.

[8] Olds, T., et al., Trends in the prevalence of childhood overweight and obesity in Australia between 1985 and 2008. International Journal of Obesity, 2010. 34(1): p. 57$57-66$.

[9] Hughes, A., et al., Incidence of obesity during childhood and adolescence in a large contemporary cohort. Preventive Medicine, 2011. 52(5): p. 300-304.

[10] Patton, G., et al., Overweight and Obesity Between Adolescence and Young Adulthood: A 10-year Prospective Cohort Study. Journal of Adolescent Health, 2011. 48(3): p. $275-280$.

[11] Davison, K. and L. Birch, Predictors of fat stereotypes among 9-year-old girls and their parents. Obesity Research, 2004. 12(1): p. 86-94.

[12] Wake, M., et al., Comorbidities of overweight/obesity experienced in adolescence: longitudinal study. Archives of Disease in Childhood, 2010. 95(3): p. 162-168.

[13] National Health and Medical Research Council, Overweight and obesity in adults and in children and adolescents - a guide for general practitioners. 2003, Australian Government, Department of Health, NHMRC: Canberra. p. Appendix - Weight Management Plan.
[14] Board of Studies, Board of Studies Years 7-10 Syllabus Course Descriptions, B.o.S. NSW, Editor. 2007, Australian Government. p. 28.

[15] Board of Studies, Personal Development, Health and Physical Education K-6 Syllabus, B.o.S. NSW, Editor. 2007, Board of Studies NSW, Australian Government.

[16] Neumark-Sztainer, D., Obesity and eating disorder prevention: an integrated approach? Adolescent medicine (Philadelphia, Pa.), 2003. 14(1): p. 159-173.

[17] Givens, A. and M. Solomon, Physical Educators' Perceptions of Obesity and Performance Expectations, in AAHPERD. 2010, Society of Health and Physical Educators America (SHAPE): Indianapolis.

[18] O'Brien, K., J. Hunter, and M. Banks, Implicit anti-fat bias in physical educators: physical attributes, ideology and socialization. International Journal of Obesity, 2007. 31(2): p. 308-14.

[19] Greenleaf, C. and K. Weiller, Perceptions of Youth Obesity among Physical Educators. Social Psychology of Education : An International Journal, 2005. 8(4): p. $407-$ 423.

[20] Rukavina, P. and W. Li, School physical activity interventions: do not forget about obesity bias. Obesity Reviews, 2008. 9(1): p. 67-75.

[21] Puhl, R. and J. Latner, Weight Bias: New Science on an Significant Social Problem. Obesity, 2008. 16(S2): p. S1-S2.

[22] O'Brien, K., et al., Obesity discrimination: the role of physical appearance, personal ideology, and anti-fat prejudice. International Journal of Obesity, 2012. 37: p. 455-460.

[23] Wright, J. and R. Welch, Tracing discourses of health and the body: exploring pre-service primary teachers' constructions of 'healthy' bodies. Asia-Pacific Journal of Teacher Education, 2011. 39(3): p. 199-210.

[24] O'Dea, J., Evidence For A Self-Esteem Approach In The Prevention Of Body Image And Eating Problems Among Children And Adolescents. . Eating Disorders, 2004. 12(3): p. 225-239.

[25] Haines, J., et al., Examination of Shared Risk and Protective Factors for Overweight and Disordered Eating Among Adolescents. Archives of Pediatric Adolescent Medicine, 2010. 164(4): p. 336-343.

[26] Chambliss, H., C. Finley, and S. Blair, Attitudes toward Obese Individuals among Exercise Science Students. Medicine \& Science in Sports \& Exercise, 2004. 36(3): p. 468-474.

[27] Peters, M. and A. Jones, Perceptions of the Physical Self of Obese Children Held by Future Sport, Exercise and Physical Education Professionals. Kinesiology, 2010. 42(1): p. 36-43. 
[28] Schwartz, M., et al., Weight Bias among Health Professionals Specializing in Obesity. Obesity, 2003. 11(9): p. 1033.

[29] O'Dea, J., Prevention Of Child Obesity: First, Do No Harm. Health Education Research, 2005. 20(2): p. 259265.

[30] Walter, M., et al., Implicit and Explicit Biases toward Obesity: Perspectives of School of Education Students. Community Medicine \& Health Education, 2013. 3(3): p. $1-6$.

[31] Datar, A., R. Sturm, and J. Magnabosco, Childhood Overweight and Academic Performance: National Study of Kindergartners and First-Graders. Obesity Research, 2004. 12(1): p. 58-68.

[32] Story, M., School-based approaches for preventing and treating obesity. International Journal of Obesity 1999. 23 (Supplement 2): p. S43-51.

[33] Davison, K., et al., Overweight Girls Who Internalize Fat Stereotypes Report Low Psychosocial Well-being. Obesity, 2008. 16(S2): p. S30-S38.

[34] IBM, SPSS. 2012: Armonk, NY.

[35] Cohen, J., Statistical power analysis for the behavioural sciences. 2nd ed. 1988, Hillsdale, NJ: Lawrence Erlbaum Associates.

[36] Pallant, J., SPSS Survival Manual: A step by step guide to data analysis using IBM SPSS. 5th ed. 2013, Sydney: Allen \& Unwin.

[37] Savage, M., Perceptions of childhood obesity in undergraduate students in physical education. Psychological Reports, 1995. 76(3c): p. 1251-1259.

[38] Robinson, E., L. Ball, and M. Leveritt, Obesity Bias Among Health and Non-Health Students Attending an Australian University and Their Perceived Obesity Education. Journal of Nutrition Education and Behavior, 2014.

[39] Greenleaf, C., S. Martin, and D. Rhea, Fighting Fat: How Do Fat Stereotypes Influence Beliefs About Physical Education? . Obesity, 2008. 16(S2): p. S53-S59.

[40] De Caroli, M. and E. Sagone, Anti-fat Prejudice and Stereotypes in Psychology University Students. Procedia Social and Behavioral Sciences, 2013. 84: p. 1184-1189.

[41] Martinek, T.J., Psycho-social dynamics of teaching physical education. 1997, Dubuque, IA: Brown \& Benchmark Publishers.

[42] O'Brien, K., et al., Do antifat attitudes predict antifat behaviors? Obesity (silver spring), 2008. 16(Supplement 2): p. S87-92. 